\title{
REFLEXIONES SOBRE EL ALCANCE TERRITORIAL DEL DERECHO AL OLVIDO
}

\section{SOME REFLECTIONS ON THE TERRITORIAL SCOPE OF THE RIGHT TO ERASURE}

\author{
ELISA TORRALBA* \\ Profesora Titular de Derecho Internacional Privado \\ Universidad Autónoma de Madrid \\ ORCID ID: 0000-0001-5813-7163
}

Recibido: 22.06.2021 / Aceptado: 06.07.2021

DOI: https://doi.org/10.20318/cdt.2021.6271

\begin{abstract}
Resumen: El "derecho de supresión", o "derecho al olvido", recogido en el artículo 17 del RGPD, puede oponerse a los gestores de motores de búsqueda como responsables del tratamiento de datos personales. En su sentencia en el asunto C- 507/17**, el TJUE afirmó el alcance geográfico limitado de este derecho, exigible en el territorio de la Unión Europea, sin cerrar, no obstante, la puerta a una posible extensión mundial en circunstancias excepcionales. Este trabajo se dedica al análisis del alcance espacial del derecho al olvido y propone una posible lectura de la cuestión desde la perspectiva del Derecho internacional privado.
\end{abstract}

Palabras clave: Protección de datos, derecho al olvido, alcance territorial.

Abstract: The "right to erasure", or "right to be forgotten", enshrined in Article 17 of the GDPR, can be enforced against search engine operators as controllers of personal data. In its judgment in Case C-507/17, the CJEU concluded the limited geographical scope of this right, enforceable in the territory of the European Union, without, however, closing the door to a possible worldwide extension in exceptional circumstances. This paper is dedicated to the analysis of the spatial scope of the right to be forgotten and proposes an alternative reading of the issue from the perspective of private international law.

Keywords: data protection, right to be forgotten, territorial scope.

Sumario: I. Introducción. II. Alcance del derecho al olvido. 1.- Contexto en el que se plantea la cuestión. 2.- El ámbito de aplicación territorial del RGPD. 3.- Aplicación espacial del derecho al olvido. 3.1- Finalidad del RGPD. 3.2.- La posición del TJUE. 4.- Un derecho al olvido de dimensión europea: consecuencias sobre la aplicación de las normas. 4.1- Primera perspectiva: lectura desde el Derecho internacional público. 4.2.- Segunda perspectiva: lectura desde el Derecho internacional privado. A.- La ley del Estado para el que se reclama la protección. B.- Las excepciones a las que se refiere la sentencia en el asunto C-507/17. III. Conclusiones. IV.- Bibliografía.

\footnotetext{
*Este trabajo se desarrolla en el marco del Proyecto de investigación financiado por el Ministerio de Ciencia, Innovación y Universidades, titulado "Protección transfronteriza de la transmisión de datos personales a la luz del nuevo Reglamento europeo: problemas prácticos de aplicación”, PGC2018-096456-B-I00.

${ }^{* *}$ STJUE de 24 de septiembre de 2019, en el asunto Google/CNIL, ECLI: EU:C:2019:772.
} 


\section{Introducción}

1. El artículo 17 del Reglamento general de protección de datos (RGPD) ${ }^{1}$ recoge el "derecho de supresión", o "derecho al olvido", como el derecho del interesado a obtener "sin dilación indebida del responsable del tratamiento la supresión de los datos personales que le conciernan" y la correlativa obligación del responsable de suprimir, también sin dilación indebida, los datos personales cuando concurra alguna de las circunstancias que el propio precepto enumera. Se trata, en consecuencia, de un derecho que no tiene un carácter absoluto, sino que está sujeto a que se den ciertas condiciones (art. 17.1) y no resulta aplicable en otras (art. 17.2)2.

2. Este derecho no se recogía expresamente en el texto de la Directiva $95 / 46 / \mathrm{CE}^{3}$, precedente del RGPD, si bien en la ya célebre sentencia del Tribunal de Justicia de la Unión Europea (TJUE) en el asunto C-131/12 $2^{4}$, éste entendió que su reconocimiento resultaba de lo previsto en sus artículos $12, \mathrm{~b}^{5}$ y 14,1, $\mathrm{a}^{6}$.

3. En esta sentencia el TJUE afirma la condición de "responsable del tratamiento" de los gestores de motores de búsqueda y entiende que cuando estos crean en un Estado miembro una sucursal o una filial destinada a garantizar la promoción y la venta de espacios publicitarios propuestos por ellos y cuya actividad se dirige a los habitantes de ese Estado miembro están llevando a cabo una actividad de tratamiento de datos personales en el marco de las actividades de un establecimiento del responsable de dicho tratamiento. Además, y más relevante en lo que aquí interesa, concluye que en el supuesto de que alguien aprecie que la inclusión en la lista de resultados obtenida como consecuencia de una búsqueda efectuada a partir de su nombre, de vínculos a páginas web, publicadas legalmente por terceros y que contienen datos e información verídicos relativos a su persona es incompatible con la Directiva porque tal información es inadecuada, no pertinente o es excesiva en relación con los fines del tratamiento, la información y los vínculos de dicha lista deben eliminarse.

4. Tras esta primera sentencia, el TJUE volvió a referirse al derecho al olvido, en relación con los motores de búsqueda, en el asunto C- 507/177, en el que concluyó su alcance geográfico limitado al territorio de la Unión Europea, sin cerrar, no obstante, la puerta a una posible extensión mundial en circunstancias excepcionales.

${ }^{1}$ Reglamento (UE) 2016/679 del Parlamento Europeo y del Consejo, de 27 de abril de 2016, relativo a la protección de las personas físicas en lo que respecta al tratamiento de datos personales y a la libre circulación de estos datos y por el que se deroga la Directiva 95/46/CE (DOUE L 119, de 4 de mayo de 2016).

2 Tanto en su denominación (derecho de supresión, derecho al olvido, derecho a la desindexación) como en su contenido surgen divergencias legislativas y doctrinales (ver, por ejemplo, D. LindsAY, "The right to be forgotten in European data protection law”, en N. WitZLED/D. LindSAy/M.PATERSON/s. RODRICK (eds.), Emerging Challenges in Privacy Law: Comparative Perspectives, Cambridge Intellectual Property and Information Law, Cambridge University Press, 2012, pp. 290-293 y 302-313, disponible en https://www.researchgate.net/publication/285187786_The_right_to_be_forgotten'_in_European_data_protection_law; D.J.B. SVANTESSON, "Limitless Borderless Forgetfulness? Limiting the Geographical Reach of the Right to be Forgotten”, Oslo Law Review, 2015, 2, p. 117; J.AusLoos, The Right to Erasure in EU Data Protection Law. From Individual Rights to Effective Protection, Oxford, Oxford University Press, 2020, pp. 111-113; G. VAN CALSTER/A. GonZALEZ ARREAZA/E.APERS, "Not just one, but many Rights to be Forgotten”, Internet Policy Review,2017, 7(2), en http:// https://policyreview.info/articles/analysis/not-just-one-many-rights-be-forgotten

3 Directiva 95/46/CE del Parlamento Europeo y del Consejo, de 24 de octubre de 1995, relativa a la protección de las personas físicas en lo que respecta al tratamiento de datos personales y a la libre circulación de estos datos (DO L 281, de 23 de noviembre de 1995).

${ }^{4}$ STJUE de 13 de mayo de 2014, Google/AEPD y Mario Costeja, ECLI:EU:C:2014:317.

5 "Derecho de acceso. Los Estados miembros garantizarán a todos los interesados el derecho de obtener del responsable del tratamiento: [...] b) en su caso, la rectificación, la supresión o el bloqueo de los datos cuyo tratamiento no se ajuste a las disposiciones de la presente Directiva, en particular a causa del carácter incompleto o inexacto de los datos [...]".

6 "Derecho de oposición del interesado. Los Estados miembros reconocerán al interesado el derecho a: a) oponerse [...], en cualquier momento y por razones legítimas propias de su situación particular, a que los datos que le conciernan sean objeto de tratamiento, salvo cuando la legislación nacional disponga otra cosa. En caso de oposición justificada, el tratamiento que efectúe el responsable no podrá referirse ya a esos datos [...]".

${ }^{7}$ STJUE de 24 de septiembre de 2019, en el asunto Google/CNIL, cit. 
5. Desde la perspectiva de la Unión Europea, el derecho al olvido se integra, junto con los demás derechos recogidos en el RGPD, en el más general del artículo 8 de la Carta Europea de derechos fundamentales, que reconoce el derecho de toda persona a la protección de los datos de carácter personal que le conciernan ${ }^{8}$. Este derecho, a su vez, tiene en la Carta carácter autónomo e independiente del reconocido en el artículo 7, referido al respeto a la vida privada y familiar ${ }^{9}$ y ambos se integran en el capítulo II, titulado "Libertades", en el que también se recoge la "libertad de expresión y de información" (artículo 11).

6. En la Carta el derecho a la protección de datos se configura como autónomo respecto de los demás, pero, como ellos, no absoluto, ya que tiene que ser leído a la luz de lo previsto en su artículo 52, que permite limitaciones al ejercicio de los derechos y libertades que la Carta reconoce siempre que estén establecidas por ley, respeten el contenido esencial de los derechos y se atengan al principio de proporcionalidad.

7. Este trabajo se dedica al análisis del alcance espacial del derecho al olvido tal y como este se configura en el artículo 17 del RGPD y tal y como lo ha entendido el TJUE. Para un mejor encaje de la cuestión, se parte de una aproximación de Derecho comparado en la que, sin ánimo de exhaustividad, se ponen de manifiesto algunas de las principales diferencias entre sistemas en la comprensión del derecho a la protección de datos, la privacidad y la libertad de expresión (II.1). Tras ello, se analiza el RGPD, su ámbito de aplicación territorial (II.2) y el papel del derecho al olvido en el contexto de esta norma para continuar con el alcance que la sentencia en el asunto C-507/17 atribuye a este derecho (II.3). El trabajo termina con una lectura de la aplicación espacial del RGPD, en lo que se refiere al derecho al olvido, que contempla una doble alternativa (II.4) y que no aspira sino a contribuir a la discusión doctrinal sobre estas cuestiones.

\section{Alcance del derecho al olvido}

\section{Contexto en el que se plantea la cuestión}

8. Como se ha puesto de relieve, el primer problema al que se enfrenta el análisis del derecho al olvido en la esfera comparada es el de las diferentes concepciones que se encuadran bajo esa denominación. En este epígrafe no pretende proporcionarse más que una muestra de las distintas aproximaciones a la protección de datos y al derecho al olvido, en sentido amplio, con la única finalidad de entender de manera más adecuada el contexto en el que el TJUE ha fijado los límites de este último y las consecuencias que de ello cabe extraer.

9. En el marco del derecho al olvido se pone de relieve de manera muy clara la diferente concepción que de la defensa de la protección de datos, y de la intimidad en general, se tiene en los distintos sistemas jurídicos, en especial en los europeos por contraposición al estadounidense. Mientras que en los primeros el derecho a la intimidad y a la protección de datos y los derechos a la información o a la libertad de expresión se sitúan en un plano de igualdad que obliga a hacer una ponderación en cada caso en el que se plantea un conflicto entre ellos ${ }^{10}$, para tratar de que los límites a que cada uno se vea some-

\footnotetext{
${ }^{8}$ El tenor literal de este artículo es el siguiente: “Artículo 8 Protección de datos de carácter personal 1. Toda persona tiene derecho a la protección de los datos de carácter personal que le conciernan. 2. Estos datos se tratarán de modo leal, para fines concretos y sobre la base del consentimiento de la persona afectada o en virtud de otro fundamento legítimo previsto por la ley. Toda persona tiene derecho a acceder a los datos recogidos que le conciernan y a obtener su rectificación. 3 . El respeto de estas normas estará sujeto al control de una autoridad independiente".

9 "Toda persona tiene derecho al respeto de su vida privada y familiar, de su domicilio y de sus comunicaciones".

${ }^{10}$ Sobre esta cuestión, y en relación con la posición del TJUE, Y. Miadzvetskaya/G. Van Calster, "Google at the Kirchberg Dock. On Delisting Requests, and on the Territorial Reach of the EU's GDPR”, European Data Protection Law Reiew, vol. 6, 2020, pp. 146-148.
} 
tido en aras de garantizar el otro sean los mínimos posibles y respeten un criterio de proporcionalidad, en Estados Unidos, los segundos priman claramente sobre el derecho a la vida privada ${ }^{11}$.

10. En Estados Unidos, la legislación federal no reconoce un derecho al olvido de manera explíci$\operatorname{ta}^{12} \mathrm{y}$ tampoco lo hace su jurisprudencia ${ }^{13}$. Solo en el Estado de California, la California Consumer Privacy $\mathrm{Act}^{14}$, en vigor desde el 1 de enero de 2020, se ocupa de esta materia, en relación con los consumidores, a los que reconoce ciertos derechos sobre sus datos, incluyendo un right to delete. Esta ley se inspira en el RGPD y construye las limitaciones a este derecho sobre la base de las contempladas en el texto europeo ${ }^{15}$.

11. Sin embargo, no faltan quienes en Estados Unidos se muestran partidarios del reconocimiento del derecho al olvido también en aquel ordenamiento ${ }^{16}$, en ocasiones con argumentos que no pueden ser compartidos desde la óptica de la Europa continental ${ }^{17}$. A cambio, otros autores son claramente contrarios, hasta el punto de que tal derecho ha llegado a ser visto como una forma de censura, como la mayor amenaza a la libertad de expresión en internet de la próxima década ${ }^{18}$, ya casi transcurrida desde que se escribió el trabajo en que esto se afirma. Se ha criticado asimismo la imposibilidad de hacer efectivo este derecho únicamente a partir de soluciones de carácter técnico ${ }^{19}$.

12. Junto a ello, en algunos países se encuentran posiciones más matizadas. En Brasil, por ejemplo, el artículo 18 de la Ley general de Protección de Datos ${ }^{20}$, en vigor desde el 18 de septiembre de

${ }^{11}$ Sobre las distintas aproximaciones, específicamente respecto del derecho al olvido, entre otros, P.J. WATANABE; “An ocean apart: the transatlantic data privacy divide and the right to erasure", Southern California Law Review, 2017, pp. 1111-1142; L.Bode/M.L. Jones, "Do Americans Want a Right to be Forgotten? Estimating Public Support for Digital Erasure Legislation", Policy \& Internet, 2018, vol.10, núm. 3, pp. 244-264 (desde una perspectiva extra jurídica). Para una visión de Derecho comparado, F. WERro (ed.), The Right To Be Forgotten. A Comparative Study of the Emergent Rights Evolution and Application in Europe, the Americas, and Asia, Springer, Cham, 2020.

${ }^{12}$ N. O'CONNOR, "Reforming the US Approach to Data Protection and Privacy", 2018, en https://www.cfr.org/report/reforming-us-approach-data-protection

${ }_{13}$ De hecho, la primera enmienda de la Constitución de Estados Unidos prohibe expresamente que el Congreso adopte cualquier ley que limite la libertad de expresión ("Congress shall make no law respecting an establishment of religion, or prohibiting the free exercise thereof; or abridging the freedom of speech, or of the press; or the right of the people peaceably to assemble, and to petition the Government for a redress of grievances").

${ }^{14} \mathrm{https}$ ///leginfo.legislature.ca.gov/faces/codes_displayText.xhtml?division=3.\&part=4.\&lawCode=CIV\&title=1.81.5

${ }^{15}$ En la ley californiana, que únicamente protege a quienes puedan ser considerados consumidores, la supresión solo puede exigirse respecto de los datos que el empresario obtuvo directamente del interesado y está sujeta a unos límites similares a los previstos en el RGPD (párrafo 1798.105)..

${ }^{16}$ M.L. Jones, The right to be forgotten, New York University Press, Nueva York/Londres 2016, pp. 189 y ss; No abogan por este derecho, pero tampoco lo rechazan, P. Bernal, “The EU, the US and Right to Be Forgotten”, en S. GurTwiRTH/R. Leenes/P. Dettert (eds.), Reloading Data Protection, Springer, Dordrecht, 2014, pp. 61-77. Para este autor, más que de una confrontación entre la libertad de expresión y la privacidad, se trata de un conflicto de culturas (espec. p. 69), contexto en el que, al menos en EEUU, también juega un papel importante la libertad de empresa (pp. 71-72), o D. Solove, "Is the right to be forgotten goor or bad? This is the wrong question", en https:/teachprivacy.com/right-forgotten-good-bad-wrong-question/y en The Future of Reputation: Gossip, Rumor, and Privacy on the Internet, Yale University Press, 2007, disponible en https://ssrn. com/abstract=2899125. Partidario de una aproximación de las posiciones entre los distintos sistemas, S.C. BENNET, "The Right to Be Forgotten: Reconciling EU and US Perspectives", Berkeley Journal of International Law, 2012, Vol. 30, pp. 161-195.

${ }_{17}$ Así, por ejemplo, se parte, en muchos casos, de la afirmación de un derecho de propiedad sobre los datos: J. RITTER/A. MaYer, "Regulating Data as Property: A new Construct for Moving Forward", Duke Law Technology Review, 2017, p. 221; J. LUND, "Property Rights to Information", Northwestern Journal of Thechnology and Intellectual Property, 2011, vol. 10, núm. 1, passim; R.T. Nimmer/P.A. Krauthaus, "Information as Property Databases and Commercial Property". International Journal of Law and Information Technologies, vol. 1, núm. 1, 1993, pp. 5-7. Para una descripción de las diferentes concepciones en Europa, Estados Unidos y China, ver J. HUANG, "COVID 19 and Applicable Law to Transnational Personal Data: Trends and Dynamics”, The Univesrity of Sydney Law School, Legal Studies Research Paper Series, núm. 20/23, abril 2020, https://papers.ssrn.com/sol3/papers.cfm?abstract_id=3570178. Por otra parte, v. JACOB entiende que incluso el RGPD (en poyecto cuando se escribió el artículo) crea de facto un régimen de propiedad sobre los datos ("The EU General Data Protection Regulation: Towars a Property Regime for Protecting Data Privacy”, The Yale Law Journal, 2013, vol. 123, núm. 2, p. 515).

18 J. Rosen, "The right to be forgotten", 64 Standford Law Review Online, 2012, p. 88.

19 D. LindsaY, "The right to be forgotten...", cit., pp. 298-299.

${ }^{20}$ Lei Geral de Proteção de Dados, núm. 13.709, de 14 de agosto de 2018, http://www.planalto.gov.br/ccivil_03/_ato20152018/2018/lei/L13709compilado.htm. 
2020, reconoce el derecho del titular de los datos a exigir su eliminación en ciertas circunstancias. Sin embargo, en una reciente sentencia, el Supremo Tribunal Federal de aquel país concluye que el derecho al olvido, concebido como el poder de oponerse, por razón del paso del tiempo, a la divulgación de hechos o datos verídicos y lícitamente obtenidos y publicados en medios de comunicación social, analógicos o digitales, es incompatible con la Constitución brasileña. A juicio del tribunal, los eventuales excesos o abusos en el ejercicio de las libertades de expresión e información deben ser analizados caso por caso partir de los parámetros constitucionales, especialmente el derecho al honor, la propia imagen, la privacidad y los derechos de la personalidad en general y de las específicas previsiones legales en los ámbitos penal y civil ${ }^{21}$. La especificidad de los hechos enjuiciados, la emisión en un canal de televisión de información sobre un crimen acaecido en Río de Janeiro unos años antes, puede estar condicionando la respuesta del tribunal por lo que, muy probablemente, no pueda desprenderse de este asunto una negativa absoluta del Derecho brasileño a la aceptación del derecho al olvido, basado en el paso del tiempo, y sus efectos sobre la información relativa a un individuo, en ciertas circunstancias.

13. En ese país, alguna sentencia anterior (y, en consecuencia, dictada también antes de la entrada en vigor de la Ley General de Protección de Datos) reconocía que, si bien el derecho al olvido se estaba consolidando en el ámbito doctrinal, e incluso se había reconocido en algún supuesto jurisprudencial, no procedía reconocerlo frente a los motores de búsqueda, puesto que eso sería convertirles en censores digitales. El tribunal entendía en ese caso que el contexto en el que actuaba no era el mismo que aquel en el que se movía el TJUE, ya que en Brasil no había una norma que amparase el derecho al olvido ${ }^{22}$.

14. En el extremo opuesto se encuentra la Ley rusa 1057337-7, de Reforma de la Ley de Datos personales, publicada en el Diario Oficial el 30 de diciembre de $2020^{23}$ y que entró en vigor el 21 de marzo de 2021 para unas cuestiones y lo hará el 1 de julio del mismo año para otras. En este país el derecho al olvido se reguló ya en 2015 en una ley especial, que contemplaba este derecho fuera del contexto general de la protección de datos. La Ley 264-FZ, de julio de 2015, en vigor desde el 1 de enero de 2016, que concede a los ciudadanos rusos el derecho a solicitar la desindexación de los resultados de búsquedas que conduzcan a información irrelevante o inexacta sobre ellos, no contiene una regulación completa sobre protección de datos personales, sino que introduce un derecho al olvido sui generis que no se ve limitado por el derecho del público de acceder a la información, ni contempla excepciones similares a las recogidas en el RGPD ${ }^{24}$.

15. En India, la sección 27 de la Personal Data Protection Bill de 2019 reconoce el derecho al olvido a favor del titular de los datos que puede, en determinadas circunstancias, solicitar del responsable (data fiduciary) que restrinja la difusión de sus datos personales.

16. Frente a lo anterior, la consagración legislativa del derecho al olvido en la Unión europea es, como se ha visto, reciente y su alcance no ha estado exento de discusión. Durante la elaboración del RGPD se debatió, por ejemplo, la posible obligación del responsable del tratamiento de informar a otros responsables acerca de la solicitud del interesado, obligación que en el texto final se mantiene solo "teniendo en cuenta la tecnología disponible y el coste de su aplicación", frente a las posiciones de quienes pretendían atribuirle un carácter más exigente. Del mismo modo, se suprimió toda referencia a que el derecho se

\footnotetext{
${ }^{21}$ Sentencia de 11 de febrero de 2021, en el recurso extraordinario .010.606, Río de Janeiro, https://portal.stf.jus.br/processos/downloadPeca.asp?id=15346473757\&ext $=$.pdf

${ }_{22}$ Sentencia del Tribunal Superior de Justicia, de 10 de noviembre de 2016, en el recurso especial $\mathrm{n}^{\circ}$ 1.593.873- SP (2016/0079618-1), https://stj.jusbrasil.com.br/jurisprudencia/862954456/agravo-interno-no-recurso-especial-agint-no-resp1593873-sp-2016-0079618-1/inteiro-teor-862954466

${ }_{23}$ Una traducción (no official) al inglés de esta ley puede encontrarse en https://www.dataguidance.com/sites/default/files/ en_20190809_russian_personal_data_federal_law_2.pdf

${ }^{24}$ R. nURUllaev, "Right to Be Forgotten in the European Union and Russia: Comparison and Criticism", Pravo. Zhurnal Vysshey shkoly economiki, 2015, no 3, pp. 181-193.
} 
aplicaría especialmente en lo que respecta al tratamiento de los datos personales que el interesado hubiera proporcionado siendo niño, para darle un alcance claramente más general ${ }^{25}$. En este contexto, el Derecho de la Unión europea se erige en el más protector de los datos personales de nuestro entorno.

\section{El ámbito de aplicación territorial del RGPD}

17. En este escenario, el artículo 3 del RGPD delimita su ámbito de aplicación territorial en términos más amplios de lo que lo hacía la Directiva 95/46/CE. El RGPD se aplica tanto al "tratamiento de datos personales en el contexto de las actividades de un establecimiento del responsable o del encargado en la Unión, independientemente de que el tratamiento tenga lugar en la Unión o no", como al "tratamiento de datos personales de interesados que residan en la Unión por parte de un responsable o encargado no establecido en la Unión, cuando las actividades de tratamiento estén relacionadas con: a) la oferta de bienes o servicios a dichos interesados en la Unión, independientemente de si a estos se les requiere su pago, o b) el control de su comportamiento, en la medida en que este tenga lugar en la Unión". A ello se añade que el RGPD se aplica asimismo al "tratamiento de datos personales por parte de un responsable que no esté establecido en la Unión sino en un lugar en que el Derecho de los Estados miembros sea de aplicación en virtud del Derecho internacional público".

18. De este modo, y siguiendo un camino ya allanado por el TJUE en el asunto C-131/12, el RGPD afirma su carácter extraterritorial, en la medida en que no se aplica únicamente a encargados o responsables con establecimiento en la Unión Europea, o en un lugar en el que el Derecho de los Estados miembros sea de aplicación en virtud del Derecho internacional público, sino también a establecidos en terceros Estados cuando el interesado resida en la Unión y la actividad del responsable o encargado se dirija a la Unión y alcance a tales interesados.

19. La aplicación a responsables y encargados del tratamiento con establecimiento en la Unión Europea parte de una noción de establecimiento que no está definida en el texto articulado del RGPD, pero sí en su Exposición de Motivos, cuyo considerando 22 señala que "establecimiento implica el ejercicio de manera efectiva y real de una actividad a través de modalidades estables. La forma jurídica que revistan tales modalidades, ya sea una sucursal o una filial con personalidad jurídica, no es el factor determinante al respecto". Este concepto amplio está en línea con el que había venido sosteniendo el TJUE $^{26}$. El texto articulado sí recoge, sin embargo, el concepto de "establecimiento principal”"27.

20. Siguiendo esa aproximación, el requisito de estabilidad conduce a rechazar la existencia de un establecimiento en situaciones en las que en la Unión Europea se pueda acceder al sitio de internet de una empresa de un tercer Estado, sin esa presencia efectiva, real y estable ${ }^{28}$. Junto a ello, el tratamiento

${ }_{25}$ Ver, a título ilustrativo, el Proyecto de resolución legislativa del Parlamento Europeo sobre la Propuesta de Reglamento (COM(2012)0011-C7-0025/2012-2012-0011(COD), en https://www.europarl.europa.eu/doceo/document/A-7-2013-0402_ ES.html.

26 Por ejemplo, en su sentencia en as. C-131/12, cit; o en las de 1 de octubre de 2015, as. C-230/14, Weltimmo (ECI:EU:C:2015:639); 28 de julio de 2016, as. C- 191/15, Verein für Konsumenteninformation (ECLI:EU:C:2016:612) y de 5 de junio de 2018, as. C- 210/16, Wirtchaftsakademie, ECLI:EU:C:2018:388).

${ }^{27}$ Este artículo distingue entre el establecimiento principal del responsable y el del encargado del tratamiento. Si el primero tiene un establecimiento en más de un Estado miembro, el principal es "el lugar de su administración central en la Unión, salvo que las decisiones sobre los fines y los medios del tratamiento se tomen en otro establecimiento del responsable en la Unión y este último establecimiento tenga el poder de hacer aplicar tales decisiones, en cuyo caso el establecimiento que haya adoptado tales decisiones se considerará establecimiento principal". En el caso del encargado será establecimiento principal "el lugar de su administración central en la Unión o, si careciera de ésta, el establecimiento del encargado en la Unión en el que se realicen las principales actividades de tratamiento en el contexto de las actividades de un establecimiento del encargado, en la medida en que el encargado esté sujeto a obligaciones específicas con arreglo al presente Reglamento".

28 "Directrices 3/2018 relativas al ámbito de aplicación territorial del RGPD (artículo 3)", de 12 de noviembre de 2019, p.7, https://edpb.europa.eu/our-work-tools/our-documents/guidelines/guidelines-32018-territorial-scope-gdpr-article-3-version_es 
de los datos debe tener lugar "en el contexto de las actividades" del establecimiento, aunque no lo realice él mismo ${ }^{29} \mathrm{y}$ sin que sea relevante que el tratamiento tenga lugar en la Unión o no.

21. Por otra parte, el artículo 3.1 no limita la aplicación del RGPD al tratamiento de datos personales de particulares que residan en la Unión Europea, requisito sí exigido en el artículo 3.2 cuando contempla la aplicación de RGPD a responsables o encargados no establecidos en ella, si bien las diferencias lingüísticas entre las distintas versiones del texto europeo obligan a introducir matices sobre los que se vuelve más adelante.

22. Junto a esa primera situación, los responsables o encargados no establecidos en la Unión Europea están sujetos al RGPD si las actividades de tratamiento están relacionadas con la oferta de bienes o servicios a los interesados en la Unión Europea, con o sin remuneración, o con el control de su comportamiento si este tiene lugar dentro aquella.

23. Este criterio de aplicación es el que puede suscitar más reticencias en vista del alcance atribuido a la norma. No obstante, y sin ánimo de entrar en la cuestión general de la aplicación extraterritorial de las leyes y las aproximaciones que desde el Derecho internacional público puedan hacerse ${ }^{30}$, lo cierto es que no estamos ante una técnica extraña si tenemos en cuenta, por ejemplo, el modo en que se aplican las reglas en materia de defensa de la competencia de la Unión Europea ${ }^{31}$, aunque esta última sea una comparación que el Abogado General Szpunar considera no pertinente en sus conclusiones al asunto C-507/1732.

24. Como en ese sector, y en aplicación de una suerte de teoría de los efectos, que reconoce la facultad de los Estados de regular comportamientos que, aunque no tengan lugar en su territorio, produzcan en él efectos sustanciales, resulta admisible la extensión, también a sujetos responsables o encargados establecidos fuera de la Unión Europea, de las obligaciones que resultan del RGPD, siempre que su actividad produzca efectos suficientemente relevantes en dicho territorio. Desde esta perspectiva, las circunstancias que el artículo 3.2 del RGPD exige para extender la aplicación del texto europeo resultan suficientes y adecuadas para afirmar la existencia la vinculación del supuesto con el territorio de la Unión Europea.

25. No obstante, y para paliar los efectos de esa doctrina, que aplicada sin límites en el contexto de internet conduciría a que cualquier Estado pudiera reclamar resultar afectado por contenidos accesibles a través de la red, fuera cual fuera el lugar del mundo en el que se hubieran originado ${ }^{33}$, se introducen ciertos matices.

26. La aplicación a quienes llevan a cabo actividades de tratamiento relacionadas con la oferta de bienes o servicios en la Unión Europea parte del requisito fundamental de la selección deliberada de

29 "Directrices 3/2018 ...", que añaden que ese requisito no debe ser objeto de una interpretación restrictiva (pp. 8).

30 Sobre esta cuestión, en el ámbito que nos ocupa, M. TAYLOR, "The EU's human rights obligations in relation to its data protection laws with extraterritorial effect”, Intl. Data Privacy Law, 2015, vol. 5, núm. 4, pp. 246-256 ; B. VAN ALSENOY/M. Kоеккоек, "Internet and jurisdiction after Google Spain: the extraterritorial reach of the right to be delisted", Intl. Data Privacy Law, 2015, vol. 5, núm. 2, pp. 105-120; D.J. SvANTESSON, "Extraterritoriality in the context of data privacy regulation", Masaryk University Journal of Law and Technology, 2013, vol. 7, pp. 87-96).

31 P. Behrens, "The extraterritorial reach of EU competition law revisited: The "effects doctrine" before the ECJ", Discussion paper, No 3/16, Europa-Kolleg Hamburg, Institute for European Integration, 2016, https://europa-kolleg-hamburg. de/wp-content/uploads/2016/11/DP_3_16_Behrens.pdf; R.P. Alford, The Extraterritorial Application of Antitrust Laws: The United States and the European Community Approaches, Virginia Journal of International Law, 1992, vol. 33, pp. 1-50; B. ZELGER, "EU Competition law and extraterritorial jurisdiction - a critical analysis of the ECJ's judgement in Intel", European Competition Journal, 2020, vol. 16 (2,3), 613-627.

32 Apartado 53 de las Conclusiones, presentadas el 10 de enero de 2019, ECLI:EU:C:2019:15.

Apartados 76 y 77 de las Conclusiones.

33 B. Van Alsenoy/M. Koekkoek, "Internet and the Jurisdiction...", cit., p. 110. 
personas en ella, de modo que lo relevante no es tratar datos personales de un individuo en la Unión, sino que eso se haga como consecuencia de una voluntad de dirigirse a los "destinatarios" en su territorio, bien ofreciéndoles bienes o servicios, bien realizando un seguimiento de su comportamiento. En relación con esto, el Considerando 23 del RGPD aclara que "si bien la mera accesibilidad del sitio web del responsable o encargado o de un intermediario en la Unión, de una dirección de correo electrónico u otros datos de contacto, o el uso de una lengua generalmente utilizada en el tercer país donde resida el responsable del tratamiento, no basta para determinar dicha intención, hay factores, como el uso de una lengua o una moneda utilizada generalmente en uno o varios Estados miembros con la posibilidad de encargar bienes y servicios en esa otra lengua, o la mención de clientes o usuarios que residen en la Unión, que pueden revelar que el responsable del tratamiento proyecta ofrecer bienes o servicios a interesados en la Unión".

27. Con esas afirmaciones, el RGPD proyecta, sin asimilarlas totalmente, a estas situaciones el criterio sostenido por el TJUE en relación con el concepto de "actividad dirigida" para la calificación de los litigios en materia de consumo a efectos de la aplicación del Reglamento 12115/2012 ${ }^{34}$. En línea con esta interpretación, cuando los bienes o servicios se prestan involuntariamente o por casualidad a una persona en el territorio de la Unión, el tratamiento conexo de los datos personales no entra en el ámbito de aplicación territorial del RGPD ${ }^{35}$.

28. El segundo tipo de actividad que da lugar a la aplicación del RGPD, en virtud de su artículo 3,2 , es el control del comportamiento de los interesados, en la medida en que este tenga lugar en la Unión Europea. Para determinar si estamos en esa situación debe evaluarse si las personas físicas son objeto de un seguimiento en internet, "inclusive el potencial uso posterior de técnicas de tratamiento de datos personales que consistan en la elaboración de un perfil de una persona física con el fin, en particular, de adoptar decisiones sobre él o de analizar o predecir sus preferencias personales, comportamientos y actitudes"36.

29. Aunque para estos casos no se exige expresamente la intención de "selección de destinatarios" por parte del responsable o del encargado del tratamiento, el uso del término "control" implica la existencia de un objetivo específico para la recogida y reutilización de los datos, lo que parece hacer necesario valorar el tratamiento que el responsable hace de los datos y si se realiza cualquier análisis posterior del comportamiento o si se utilizan técnicas de elaboración de perfiles con dichos datos ${ }^{37}$.

30. Por otra parte, el artículo 3, 2 se refiere a "los datos personales de interesados que residan en la Unión" y, sin embargo, el considerando 14 establece que "la protección otorgada por el presente Reglamento debe aplicarse a las personas físicas, independientemente de su nacionalidad o de su lugar de residencia, en relación con el tratamiento de sus datos personales", en coincidencia con el tenor literal de otras versiones lingüísticas del mencionado precepto ${ }^{38}$. Estas versiones se adecuan mejor al Derecho primario de la Unión Europea, que establece un amplio ámbito de protección de los datos personales, que no se limita a los ciudadanos de la Unión: el artículo 8 de la Carta de los Derechos Fundamentales establece que el derecho a la protección de los datos personales no está limitado, sino que se aplica a "toda persona".

\section{Aplicación espacial del derecho al olvido}

31. La delimitación del ámbito de aplicación territorial del RGPD en términos tan amplios podría llevarnos a considerar que los derechos que este recoge se aplican con un alcance global. De este

\footnotetext{
${ }_{34}$ STJUE de 7 de diciembre de 2010, C-585/08 y C-144/09, Pammer, ECLI:EU:C:2010:740.

35 "Directrices 3/18...", p. 20.

${ }^{36}$ Considerando 25 del RGPD.

37 "Directrices 3/18...", cit., p. 22.

38 "Subjects who are in the Union", en la version inglesa, "personnes concernées qui se trouvent", en la francesa, "betroffenen Personen, die sich in der Union befinden", en la alemana y "interessati qui se trovano nell'Unione", en la italiana, por ejemplo.
} 
modo, parecería razonable entender que, una vez sabemos que incluso el responsable del tratamiento establecido fuera de la Unión Europea debe aplicar el RGPD cuando trata datos personales de interesados en ella, en las condiciones previstas en su artículo 3, el eventual derecho de supresión que estos interesados pudieran querer ejercer al amparo del artículo 17 debería extenderse a la eliminación de sus datos estén o no "localizados" en la Unión Europea.

32. Se trata de una interpretación que, si bien podría resultar coherente, no se infiere necesariamente de los términos del artículo 3, que, en la medida en que exige vínculos claros con la Unión Europea, puede entenderse que limita también el alcance de los derechos que el RGPD recoge a ese mismo espacio geográfico.

33. En esta línea, la delimitación del ámbito de aplicación territorial del RGPD no coincide necesariamente con el alcance de los derechos que confiere. Es decir, una cosa es afirmar que se aplica el RGPD porque, aunque el responsable estuviera establecido fuera de la Unión Europea, dirigía su actividad a interesados localizados en ella y otra distinta que estos puedan extender los derechos que les concede el RGPD más allá de sus fronteras.

34. La cuestión ha sido abordada por el TJUE en relación con el derecho al olvido respecto de unos responsables muy específicos, los motores de búsqueda, en la ya citada sentencia en el asunto C-507/17, en la que, contra lo que algunos esperaban, ha afirmado que el RGPD no les impone, con base en su artículo 17, la retirada de enlaces a nivel global, sino solo en el ámbito de la Unión Europea, con ciertas excepciones. Como se verá, esta limitación no se justifica por razones de Derecho privado, sino que se sitúa sustancialmente en la esfera del Derecho público y en la idea de comity como elemento fundamental en las relaciones internacionales ${ }^{39}$.

35. Para comprender mejor las conclusiones que el presente trabajo deriva de esa sentencia, es necesario exponer primero la visión de partida acerca de la finalidad del RGPD y del derecho al olvido dentro de esa norma.

\subsection{Finalidad del RGPD}

36. En la Carta de Derechos Fundamentales de la Unión Europea, cada uno de los derechos recogidos es un objetivo en sí mismo, de manera que, aunque la convivencia de unos y otros exige en la práctica su ponderación en el caso concreto, aquella no recoge los términos en los que debería producirse.

37. Por otro lado, cuando su artículo 51 se refiere a su ámbito de aplicación, lo extiende únicamente a "las instituciones y órganos de la Unión, respetando el principio de subsidiariedad, así como a los Estados miembros únicamente cuando apliquen el Derecho de la Unión [...]".

38. En ese contexto se sitúa el RGPD, cuya exposición de motivos comienza con la referencia expresa al artículo 8 de la Carta de Derechos Fundamentales de la Unión Europea, de la que trae causa. Sin embargo, a diferencia de ella, el RGPD sí pretende garantizar la protección de datos en su relación con los demás derechos, estableciendo un equilibrio entre ellos. De este modo, el RGPD realiza la ponderación entre la libertad reconocida en el artículo 8 de la Carta y otros derechos o libertades recogidos en esta con los que pudiera entrar en conflicto (señaladamente las libertades de expresión e información del artículo 11 e, incluso, la libertad de empresa, reconocida en el artículo 16)), ponderación que, en la medida en que se refiere a derechos reconocidos en aquella se limita a su mismo ámbito espacial, obligando solo a las instituciones de la Unión Europea y a los Estados miembros.

39 Sigue con esto la solución propugnada por G. VAN CALSTER, "Regulating the internet. Prescriptive and Jurisdictional Boundaries to the EU's right to be forgotten", 2015, disponible en https://ssrn.com/abstract=268611, pp. 28 y 29. 
39. Más en concreto, mientras la Carta reconoce la protección de datos de carácter personal, estableciendo de manera unívoca un nivel mínimo de control del individuo sobre sus datos personales, el RGPD pretende garantizar que ese objetivo se alcanza en armonía con otros derechos y libertades fundamentales y establece, a través de legislación secundaria, la manera de alcanzar ese equilibrio, creando para ello lo que algún autor ha calificado de micro-derechos que delimitan el alcance de la libertad contemplada en el artículo $8^{40}$.

40. Como consecuencia, se crea un derecho a la protección de datos de dimensión europea y sujeto a los límites geográficos del territorio de la Unión, de tal manera que la concepción que de él se tenga y de sus relaciones con otros derechos será propia de ésta y, en principio, uniforme en los Estados miembros, salvo en los casos en los que el propio RGPD permite discrepancias.

41. Esta afirmación general se extiende especialmente al derecho al olvido, con la consecuencia de que, desde esa perspectiva, la concepción territorial del derecho al olvido recuerda a la de los derechos de propiedad intelectual e industrial que, como es conocido, limitan su alcance al territorio del Estado que los reconoce o, en caso de existir un texto europeo que pretenda una protección unitaria, al territorio de la Unión o de los Estados que participan en el texto en cuestión. Las consecuencias de esta concepción sobre las reglas de Derecho internacional privado y el paralelismo de este planteamiento con el del derecho al olvido se abordan en el epígrafe 4.

\subsection{La posición del TJUE}

42. Tras la sentencia en el asunto C- 131/12, Google/AEPD y Mario Costeja, parte de la doctrina se hizo eco de algunos de sus problemas de implementación y, en concreto, de la cuestión a la que se refiere este trabajo y que la propia sentencia no resolvía: una vez admitido que los gestores de motores de búsqueda eran responsables del tratamiento y que frente a ellos se podía ejercer el derecho de supresión o derecho al olvido, se hacía necesario determinar si este se debía limitar al ámbito estatal o si era posible su extensión a otros Estados.

43. Los autores que se ocupaban de esta materia no proporcionaban una respuesta unívoca, si bien en su mayoría coincidían en que en algunas circunstancias podía estar justificada una supresión global de enlaces. Entre los elementos a tener en cuenta para valorar la situación se incluían aspectos como el interés potencial que otros Estados pueden tener en relación con el contenido cuya supresión se solicita (si se toma como ejemplo el caso que dio lugar a la sentencia en el asunto mencionado al inicio de este epígrafe, no parece que la información cuya supresión se solicitaba fuera particularmente relevante para posibles usuarios de internet fuera de la Unión europea, o, incluso, fuera de España. A cambio, en otros supuestos, el interés será mayor: piénsese, por ejemplo, en una persona que se ha trasladado a vivir al extranjero o, incluso, que tiene una dimensión pública); el impacto adverso que pueda tener una supresión meramente local en atención a las circunstancias del caso concreto; la cuestión de hasta qué punto la norma cuyo efecto extraterritorial se pretende es compartida por otros Estados y, por último, la presencia de otros factores de conexión relevantes con el Estado que quiere imponer su ley ${ }^{41}$.

40 J. Ausloos, The Right to Erasure in EU Data Protection Law. From Individual Rights to Effective Protection, Oxford University Press, Oxford, 2020, pp. 69-70. Sobre este concepto de micro-derechos: c. LAZARo/D. Le MÉTAYER, "Control over personal data: true remedy or fairy tale?", 12 SCRIPTed, 2015, https://script-ed.org/article/control-over-personal-data-true-remedyor-fairy-tale/

${ }^{41}$ B. Van Alsenoy/M. Koеккоek, "Internet and Jurisdiction...", cit., pp. 117-119. Desde otro planteamiento, algunos autores ponen en duda la premisa de este debate y concluyen que a una mayor extensión geográfica del derecho al olvido no le sigue necesariamente una merma de la libertad de expresión e información (K. BYUNG- CHEOLI/K. JINYEUB, "The Economics of the Right to Be Forgotten”, Journal of Law and Economics, 60 (2), 2017, pp. 335-360), en contra de lo sostenido por el Abogado General Szpunar en sus Conclusiones a la sentencia en el asunto C-507/17 que ve un riesgo de nivelar a la baja en detrimento de la libertad de expresión la ponderación entre derechos si se exige la retirada global de enlaces (apartado 61). 
44. En este contexto, el TJUE vino a hacer frente a la cuestión en el asunto C-50//17. En el caso, la Commission nationale de l'informatique et des libertés (CNIL) requirió a Google, que había estimado la solicitud de una persona física para que se suprimieran de la lista de resultados obtenida tras una búsqueda efectuada a partir de su nombre los enlaces que dirigían a una serie de páginas web, para que aplicase esta suspensión respecto de todas las extensiones de nombre de dominio de su motor de búsqueda. Google se limitó a suprimir los enlaces de los resultados obtenidos a través de las búsquedas efectuadas desde los nombres de dominio correspondientes a las extensiones de su buscador en los Estados miembros de la Unión Europea y propuso un mecanismo de bloqueo geográfico consistente en eliminar la posibilidad de acceder desde una dirección IP localizada en el Estado de residencia del interesado a los resultados obtenidos a raíz de una búsqueda efectuada a partir de su nombre, independientemente de la extensión del motor de búsqueda solicitada por el internauta. Dado que CNIL consideró estas medidas insuficientes, impuso a Google una sanción, cuya nulidad ésta solicitó al Conseil d'État, que, a su vez, planteó una serie de cuestiones prejudiciales al TJUE.

45. El objeto de estas cuestiones no era otro que determinar el alcance geográfico de la obligación de supresión de enlaces, planteando una triple alternativa: su alcance global, un alcance limitado al territorio de la UE o, incluso, un alcance limitado al territorio del Estado miembro en que se haya presentado la solicitud, combinándola, en su caso, con un mecanismo de bloqueo geográfico.

46. Si bien el supuesto se planteaba en un contexto en el que todavía resultaba de aplicación la Directiva 95/46, el TJUE extendió su sentencia al RGPD, a fin de proporcionar una respuesta útil. Tras constatar que retirar los enlaces de todas las versiones de un motor de búsqueda responde plenamente al objetivo de garantizar un elevado nivel de protección de datos personales en toda la Unión, el TJUE concluye, sin embargo, que del tenor de los artículos 12, b), y 14, 1, a de la Directiva 95/46 y del artículo 17 del RGPD no se desprende que se haya optado por atribuir a los derechos consagrados en estas disposiciones un alcance que vaya más allá del territorio de los Estados miembros y que haya pretendido imponer a los gestores de motores de búsqueda la obligación de retirar enlaces también de las versiones nacionales de su motor de búsqueda que no correspondan a los Estados miembros ${ }^{42}$. No obstante, esa medida debe combinarse, en su caso, con otras que, "con pleno respeto de las exigencias legales, impidan de manera efectiva o, al menos, dificulten seriamente a los internautas que efectúen una búsqueda a partir del nombre del interesado desde uno de los Estados miembros el acceso, a través de la lista de resultados que se obtenga tras esa búsqueda, a los enlaces objeto de la solicitud de retirada" ${ }^{43}$.

47. A esa conclusión llega el TJUE partiendo de la constatación de las diferencias en el tratamiento del derecho a la retirada de enlaces en muchos terceros Estados, respecto de lo previsto en la legislación de la Unión Europea. A ello añade (i) que el derecho a la protección de los datos personales no es absoluto, sino que debe considerarse en relación con su función en la sociedad y mantener el equilibrio con otros derechos fundamentales ${ }^{44}$, sobre la base de un criterio de proporcionalidad equilibrio que varía significativamente en las distintas partes del mundo; (ii) que el legislador de la Unión ha establecido en el artículo 17 del Reglamento el equilibrio entre el respeto a la vida privada y la protección de datos personales y la libertad de información de los internautas, que es válido para la Unión, pero no extensible a otros ámbitos geográficos; (iii) que, como consecuencia de lo anterior, si bien el RGPD proporciona a las autoridades de control de los Estados miembros instrumentos y mecanismos de cooperación para llegar a una decisión común basada en el equilibrio entre los derechos a la vida privada y a la protección de datos personales y la libertad de información, no los prevé fuera de la Unión.

\footnotetext{
${ }^{42}$ Considerando 62.

43 Considerando 70

44 Sentencia de 9 de noviembre de 2010, . C92/09 y C93/09, Volker, ECLI:EU:C:2010:662, considerando 48 y Dictamen 1/15 (Acuerdo PNR UE-Canadá), de 26 de julio de 2017, ECLI:EU:C:2017:592, apartado 136.
} 
48. La referencia a los mecanismos de cooperación resulta más relevante de lo que puede parecer a partir de una primera lectura de la sentencia, puesto que a través de ellos se pretende garantizar la aplicación uniforme del RGPD que, como se verá, tiene consecuencias en las cuestiones que se analizan en las páginas siguientes. Se trata de los mecanismos previstos en los artículos 56 y 60 del RGPD que, para los tratamientos transfronterizos, y con reserva de lo dispuesto en el artículo 56, 2, prevén un procedimiento de cooperación entre las autoridades de control interesadas, que deben acudir a él para llegar a un consenso y a una decisión única, que vincula a todas esas autoridades y cuyo cumplimiento debe garantizar el responsable del tratamiento en las actividades de tratamiento en el contexto de todos sus establecimientos en la Unión Europea. No se extiende, en consecuencia, a quienes actúan sin tener en ella un establecimiento. El artículo 61.1 exige, además, que las autoridades de control se faciliten información útil y se presten asistencia mutua a fin de aplicar el RGPD de manera coherente en toda la Unión Europea, para lo que se establece un "mecanismo de coherencia" en los artículos 63 y siguientes ${ }^{45}$. Así pues, este marco reglamentario proporciona a las autoridades nacionales de control los instrumentos y mecanismos necesarios para conciliar los derechos al respeto de la vida privada y a la protección de los datos personales del interesado con el interés del conjunto del público de los Estados miembros en acceder a la información de que se trate y, de este modo, para poder adoptar, en su caso, una decisión sobre la retirada de enlaces que abarque la totalidad de las búsquedas efectuadas a partir del nombre del interesado desde el territorio de la Unión.

\section{Un derecho al olvido de dimensión intra-Unión Europea: consecuencias sobre la aplicación de las normas}

49. De todo lo anterior resulta el reconocimiento por el TJUE de que del RGPD (y antes de la Directiva) nace un derecho al olvido limitado al ámbito territorial de la Unión Europea. Paralelamente, se acepta que el contenido que se atribuye al derecho a la protección de los datos personales puede ser distinto en otros Estados, que pueden incluso negar la existencia del derecho al olvido.

50. La territorialidad se predicaría no respecto de cada Estado miembro individualmente considerado, sino de toda la Unión Europea, que crea de este modo un derecho unitario que no permite limitar el acceso a la información de quienes pretenden acceder a ella desde terceros Estados .

51. Desde esta perspectiva, el límite territorial que se impone al derecho al olvido viene a completar, al menos en lo que a dicho derecho se refiere, al artículo 3 del RGPD, de manera que este se aplica a las situaciones que contempla (responsable o encargado con establecimiento en la Unión europea y supuestos en los que, sin estar establecido en ella, se dan las circunstancias recogidas en su apartado 2) con un requisito adicional: solo en los Estados miembros de la Unión Europea.

52. A partir de esta limitación, queda abierta la cuestión de cómo resolver las situaciones no cubiertas por la norma: aquellas en las que, aunque se cumplen las condiciones del artículo 3, la protección se pretende para fuera de la Unión Europea. Dado que estos casos quedarían fuera del alcance del artículo 17 del RGPD, es necesario determinar cuál sería el ordenamiento aplicable en el supuesto de que la cuestión se planteara a un tribunal español.

53. Las consecuencias de esta configuración sobre la aplicación de las distintas leyes nacionales de protección de datos en las relaciones ad extra (Unión Europea- terceros Estados) se pueden analizar desde una doble perspectiva. La más evidente parte de un razonamiento de Derecho público, que consi-

\footnotetext{
45 Junto a ello, el artículo 66 establece un mecanismo de urgencia que permite que una autoridad de control adopte medidas provisionales destinadas a producir efectos jurídicos en su propio territorio cuando considere que es urgente intervenir para proteger los derechos y las libertades de los interesados. Estas medidas solo se pueden adoptar por un período de validez determinado que no podrá ser superior a tres meses.
} 
dera al artículo 3 del RGPD como una norma de extensión que se limita a establecer el alcance territorial del texto europeo sin pretender resolver un problema conflictual y, en consecuencia, sin que pueda servir para determinar qué ley aplicar cuando el RGPD no resulte aplicable. Pero es posible también una segunda lectura, conflictualista, que extrae consecuencias propias de Derecho internacional privado de la decisión del TJUE.

\subsection{Primera perspectiva: lectura desde el Derecho internacional público}

54. Desde esta perspectiva, cual sea el Derecho a aplicar en aquellos casos en los que, para decidir sobre el derecho al olvido, el RGPD no resulte de aplicación según los criterios acumulados que han sido expuestos, es una cuestión no resuelta.

55. La cuestión puede entenderse de manera más gráfica si se aplica la tradicional distinción anglosajona entre prescriptive jurisdiction, entendida como el poder del Estado de dictar leyes, adjudicative jurisdiction (o judicial jurisdiction), que se refiere al poder estatal de decidir, a través de sus órganos judiciales, en asuntos con un elemento extranjero y executive jurisdiction, entendido como la potestad de ejecución del Estado. Si bien el artículo 3 del RGPD parece responder a la primera de estas categorías, la cuestión que aquí nos ocupa se enmarca en la esfera de la tercera y pone de manifiesto que no necesariamente los tres aspectos de la situación tienen que estar unidos.

56. De este modo, si bien es razonable entender que si un Estado puede legislar sobre una situación y sus tribunales pronunciarse sobre ella, puede también ese Estado pretender que las consecuencias de su regulación se apliquen en el extranjero, sin que las dificultades que esa ejecución puede presentar sean necesariamente un motivo para que sus tribunales dejen de ejercer la executive jurisdiction, lo cierto es que, en la práctica, hay circunstancias que aconsejan una cierta autolimitación ${ }^{46}$. Esa autolimitación es la que establece el TJUE cuando aborda la cuestión del ámbito de aplicación espacial del derecho al olvido.

57. En esta línea, en la medida en que la principal razón por la que no extendemos la concepción de derecho al olvido que resulta del RGPD es la comity, ésta no es un obstáculo en aquellas situaciones en las que los ordenamientos de los terceros Estados en los que se pretendería la desindexación resultan compatibles con aquella concepción. Siendo así, sería posible para un tribunal europeo extender el derecho al olvido y, con él, la ponderación de intereses que hace el reglamento a Estados no miembros de la Unión Europea, en la medida en que tal extensión del derecho no choque con los parámetros nacionales de ese tercer Estado.

58. No obstante, incluso visto desde esa perspectiva, el análisis se acerca al que sería propio del Derecho internacional privado porque puede considerarse que no se trata tanto de que se extiendan los efectos del RGPD fuera de la Unión Europea, como que, de facto, estemos dando entrada al ordenamiento de ese tercer Estado, de manera que la exigencia de desindexación es posible no por mandato del RGPD, sino porque es, cuanto menos concurrentemente, bien una exigencia, bien una posibilidad admitida por la ley local (la ley del territorio para el que se solicita la desindexación). Por ello también, cuando esa ley local no admite la desindexación, no cabe exigirla.

\subsection{Segunda perspectiva: lectura desde el Derecho internacional privado}

59. En línea con lo que se viene señalando, es posible también realizar una lectura de la materia que aquí se analiza utilizando para ello categorías propias del Derecho internacional privado. Esta

${ }^{46}$ Véase sobre esta cuestión G. VAN CALSTER, "Regulating the internet...", cit. 
lectura no se aborda en la decisión del TJUE en el asunto C- 507/17, ni tampoco en la concepción que de esta cuestión tenía el legislador cuando redactó el RGPD, pero puede resultar interesante, al menos como perspectiva de análisis.

60. La visión conflictualista se aborda en algunos trabajos doctrinales, desde luego cuando se trata de determinar, dentro de los márgenes que permite el RGPD, qué ley nacional resulta aplicable ${ }^{47}$, pero también cuando se trata de las relaciones ad extra. Así, algún autor ha defendido la concepción del artículo 3 del RGPD como norma de conflicto bilateralizable, que concede al interesado el Derecho a escoger, cuando las conexiones que este artículo recoge se verifican en terceros Estados, cualquiera de las leyes a las que conducen ${ }^{48}$. No es esta la interpretación que se adopta en este trabajo, que por otra parte tiene una pretensión más limitada, restringida al derecho al olvido.

\section{A. La ley del Estado para el que se reclama la protección}

61. Como se ha apuntado en páginas anteriores, la concepción de un derecho al olvido de alcance territorial, cuyos contornos fija el RGPD para el conjunto de la Unión Europea, recuerda a la de los derechos de propiedad intelectual e industria ${ }^{49}$. Respecto de estos también se predica una extensión territorial, sea de ámbito estatal, sea, cuando hay un texto reglamentario europeo que les reconoce un efecto unitario para todo el territorio de la Unión Europea, de ámbito supraestatal.

62. En Derecho internacional privado la territorialidad de los derechos de propiedad intelectual se traduce, en el ámbito del Derecho aplicable, en la aplicación de la ley para cuyo territorio se reclama la protección, que rige tanto para las cuestiones relativas a la validez de los derechos ${ }^{50}$, como para las que se refieren a su violación ${ }^{51}$. De esta forma, quien considera su derecho vulnerado por la publicación sin su consentimiento de ejemplares de su obra impresa en Francia verá cómo se aplica el Derecho francés al enjuiciamiento de dicha vulneración y a las consecuencias de la misma. Si, por el contrario, esa protección se solicita para España, será el Derecho español el aplicable. Siendo así, se produce un efecto mosaico que obliga a aplicar varias leyes distintas si se persigue una protección global del derecho, con la consecuencia, además, de que cada una de ellas puede perfilarlo con distintos contornos o incluso no reconocerlo en ciertas circunstancias. La cuestión se vuelve más compleja cuando tal publicación se produce a través de la web, pero también en este caso la consecuencia es que puede resultar potencialmente aplicable el Derecho de todos los Estados en los que esa obra resulta accesible ${ }^{52}$.

47 M. MantovanI, "Horizontal conflicts of Member States GDPR-complementing laws: the quest for a viable conflict-oflaws solution", Rivista di diritto internazionale privato e processuale, 2019, núm. 3, pp. 535-562; J. OsTER, "Internationale Zuständigkeit und anwendbares Recht im Datenschutz", Zeitschrift für europäisches Privatrecht, 2021. Núm. 2, pp. 275-305.

${ }^{48}$ Ver, por ejemplo, C. WeNDERHORST, que apunta la posibilidad de considerar el artículo 3 del RGPD como una norma de conflicto multilateral, que operaría, no obstante, solo en el caso de que las dos conexiones a las que se refiere se verificaran fuera de la Unión Europea, otorgando al interesado la posibilidad de escoger entre las leyes estatales de cualquiera de los Estados a los ue éstas pudieran conducir ("Digitalgüter im internationalen Privatrecht", IPRax, 2020, núm. 6, p. 493). Se trata de una construcción que, más que atender al concepto de una norma de conflicto multilateral, parece responder a la bilateralización de una norma unilateral.

${ }^{49}$ Este paralelismo, que en ningún caso debe verse como una asimilación, ha sido puesto de relieve por algunos autores, entre ellos B. J. Koops, "Forgetting Footprints, Shunning Shadows. A Critical Analysis of the Right to be Forgotten in Big Data Practice”, ScriptEd, 2011, vol. 8, núm. 3, pp. 229-256, espec. p.249; P. Bernal, "The EU, the US and Right to Be Forgotten”, cit., p. 73.

${ }^{50}$ Artículo 10.4 del CC, según el que "los derechos de propiedad intelectual e industrial se protegerán dentro del territorio español de acuerdo con la ley española [...]”. Se trata una norma unilateral que se bilateraliza, aplicándose el mismo criterio cuando la protección se pretende para otros Estados.

${ }^{51}$ Artículo 8 del Reglamento 864/2007 del Parlamento Europeo y del Consejo, de 11 de julio de 2007, relativo a la ley aplicable a las obligaciones extracontractuales (Roma II), DOUE L 199, de 31 de julio de 2007. Según este artículo, "la Ley aplicable a la obligación extracontractual que se derive de una infracción de un derecho de propiedad intelectual será la del país para cuyo territorio se reclama la protección".

52 Sobre estas cuestiones, ver, por todos, P. De Miguel Asensio, Derecho Privado e internet, Thomson Reuters, Cizur Menor, 2015 
63. El paralelismo es solo relativo, no únicamente por el distinto carácter de los derechos en presencia, sino, sobre todo, porque en el ámbito de los derechos de propiedad intelectual e industrial existe un amplio consenso internacional sobre su protección, de manera que, aunque existen divergencias entre Estados en su regulación, se parte de unos principios mínimos comunes, lo que, como se ha visto, está lejos de ocurrir en el ámbito de la protección de datos.

64. No obstante, puede resultar útil trasladar a cuanto aquí nos ocupa ese modelo de análisis, con la conclusión de que quien alega la vulneración de su derecho a la protección de datos personales como consecuencia de la aparición de ciertos datos relativos a su persona cuando se introduce su nombre en un motor de búsqueda, información que resulta accesible desde todo el mundo (al menos potencialmente), resultará protegido por el RGPD solo en el ámbito de la Unión Europea, de manera que el derecho a que esos datos sean eliminados se producirá solo en los nombre de dominio correspondientes a la Unión o a los propios Estados miembros, pero no en los de terceros, sin perjuicio de la posibilidad de usar mecanismos de geobloqueo ${ }^{53}$.

65. No se pretende, a través de esta propuesta, defender una calificación de los datos como bienes susceptibles de ser objeto de derecho de propiedad, concepción más propia de la órbita anglosajona $^{54}$, pero no puede dejar de destacarse que esta lectura alternativa que se propone encuentra un encuadre posible tanto en los sistemas que parten de esa concepción, como en la lógica de la Unión Europea, donde prima el carácter de derecho fundamental de la protección de los datos personales, si se parte de la premisa, ya expuesta, de la limitación del derecho desde el propio ordenamiento de la Unión.

66. De este modo, la cuestión sería la siguiente: el artículo 3 del RGPD no actúa al margen de las normas de conflicto, sino que se limita a determinar el ámbito de aplicación del texto europeo cuando es llamado por aquéllas, que operan con carácter previo. Dado, según esta lectura, que el propio RGPD no contiene una norma de conflicto para las relaciones ad extra, es necesario acogerse a las generales, ya existentes.

67. Partiendo de una calificación extracontractual del derecho al olvido, desde la perspectiva española, la norma de conflicto hay que buscarla en el artículo 10.9 del Código Civil, dada la exclusión del ámbito de aplicación del Reglamento sobre la ley aplicable a las obligaciones extracontractuales (Roma II $)^{55}$ de "los derechos que se deriven de la violación de la intimidad o de los derechos relacionados con la personalidad [...]”,en virtud de su artículo 1.2,g.

68. La referencia del artículo 10.9 del Código Civil a "la ley del lugar donde hubiere ocurrido el hecho de que deriven" como criterio de conexión para determinar la ley aplicable a las obligaciones no contractuales, es, como es bien sabido un concepto susceptible de interpretaciones que se adecúen a las necesidades de los distintos supuesto ${ }^{56} \mathrm{y}$ habría que entenderla, cuando lo que se pretende es ejercer el derecho al olvido, como el lugar para cuyo territorio se reclama la protección porque, no existiendo

53 Ver al respecto, A. López TARRUella, que plantea la incompatibilidad de los mecanismos de geobloqueo con el Reglamento 2018/302, de 28 de febrero de 2018, sobre medidas destinadas a impedir el bloqueo geográfico injustificado y otras formas de discriminación por razón de la nacionalidad, del lugar de residencia o del lugar de establecimiento de los clientes en el mercado interior y por el que se modifican los Reglamentos (CE) n.o 2006/2004 y (UE) 2017/2394 y la Directiva 2009/22/CE, DOUE L 60, de 2 de marzo de 2018 (en "El ámbito territorial de la protección de los derechos de la personalidad en el entorno de internet (a propósito de las sentencias del TJUE de 24 de septiembre de 2019, C-507/17, Google, y de 3 de octubre de 2019, C-18/18, Glawischnig-Piesczek)”, Revista Electrónica de Estudios Internacionales, 2019, núm. 38, p. 35.

${ }^{54}$ Vid. cita 19 supra.

55 Reglamento 864/2007, de 11 de julio de 2007, (DOUE L 199, de 31 de julio de 2007).

56 De ello es un claro ejemplo la jurisprudencia del TJUE, que, cuando interpreta ese mismo concepto en aplicación de otras normas, sustancialmente el Reglamento 1215/2012, del Parlamento Europeo y del Consejo, de 12 de diciembre de 2012, relativo a la competencia judicial, el reconocimiento y la ejecución de resoluciones en materia civil y mercantil (DOUE L 351, de 20 de diciembre de 2012)- Reglamento Bruselas I bis, concreta ese lugar de maneras distintas, pero coherentes entre sí, en función de la naturaleza del litigio de que se trate. 
un derecho al olvido de alcance universal, este solo podrá ser vulnerado allí donde existe, de manera que nadie puede pretender violado su derecho a la supresión de enlaces en Estados Unidos cuando este ordenamiento afirma su no existencia.

69. La conclusión es que frente a un responsable o encargado del tratamiento con un establecimiento en la Unión Europea o que dirige sus actividades a interesados en ella (cumpliendo los requisitos del artículo 3) se aplicará el Reglamento cuando la protección se reclame para la Unión Europea y el Derecho de cada uno de los demás Estados en los que se pueda pretender la retirada de enlaces para determinar si esta procede o no. Esta solución se proyectaría no solo a los casos en los que se quiere ejercer el derecho al olvido, sino también a aquellos en los que se reclama una indemnización por el daño que genera no atender a esta petición en un primer momento, cuando debería haberse hecho.

70. El hecho de que las normas de conflicto en esta materia no estén armonizadas en el seno de la Unión Europea podría resultar un obstáculo a este planteamiento, en la medida en que se haría depender la aplicación del RGPD de criterios conflictuales nacionales. No obstante, la aplicación de la lex loci damni a los ilícitos extracontractuales es una solución generalmente aceptada en Derecho comparado y la interpretación que de la misma se propone resultaría también admisible en todos ellos, sobre todo en la medida en que resulta, para este caso, de la interpretación de la jurisprudencia del TJUE.

71. En cualquier caso, la interpretación apuntada puede propugnarse como una posible solución de lege ferenda, que pasaría por modificar el Reglamento Roma II para eliminar la exclusión de los derechos de la personalidad ${ }^{57}$, estableciendo para la protección de datos una regla especial con el tenor que se viene indicando y sin necesidad de excluir la posibilidad de acudir a la autonomía de la voluntad limitada que reconoce su artículo 14.

\section{B. Las excepciones a las que se refiere la sentencia en el asunto C- 507/17}

72. La construcción resulta hasta aquí relativamente simple. No obstante, en la sentencia en el asunto C-507/17, el TJUE añade a la conclusión que hasta aquí se ha expuesto, dos excepciones: no se excluye que, en virtud de la ponderación de derechos realizada según los estándares de protección nacionales, un Estado miembro pueda exigir al gestor del motor de búsqueda que proceda a retirar los enlaces de todas las versiones de dicho motor. Es esta última una consecuencia que el RGPD no exige, pero tampoco prohíbe. En segundo lugar, si bien la retirada de enlaces debe verificarse, en principio, en todos los Estados miembros, el interés del público en acceder a la información puede variar de un Estado a otro, por lo que precisamente en virtud de la ponderación nacional mencionada, en ocasiones cabrá que la obligación de supresión de enlaces se limite al territorio de uno, o varios, Estados. Desde mi punto de vista, y contra algunas reacciones que suscitó la sentencia, resulta más fácil compartir el criterio principal de la sentencia ${ }^{58}$ que las dos exclusiones que contempla y. especialmente, la que admite la posibilidad de un derecho al olvido de límite puramente estatal dentro de la Unión Europea.

73. Los casos en los que cada una de estas excepciones se van a aplicar quedan lejos de resultar claros. En primer lugar, y en relación con la primera de ellas, se justifica en que el artículo 17 de RGPD excluye de la aplicación del derecho al olvido, entre otros, el supuesto en el que el tratamiento sea necesario "para ejercer el derecho a la libertad de expresión e información" y que el artículo 85 del mismo texto deja en manos de los Estados miembros la conciliación del derecho a la protección de datos

\footnotetext{
57 Exclusión que nunca se debería haber producido (sobre ella, E. TorRALBA; "La difamación en la era de las comunicaciones: ¿Nuevas? Perspectivas de Derecho internacional privado”, InDret, 2012, https://indret.com/la-difamacion-en-la-era-delas-comunicaciones-nuevas-perspectivas-de-derecho-internacional-privado-europeo/).

58 En contra, J. Globocnick, "The Right to Be Forgotten is Taking Shape: CJEU Judgments in GC and others (C-136/17) and Google v CNIL (C-507/17)”, GRUR International, 2020, 69(4), p. 386.
} 
personales en virtud del Reglamento y el derecho a la libertad de expresión e información, conciliación que deberá hacerse "por ley" y podrá suponer excepciones a los derechos contenidos en el artículo 3 , entre ellos el derecho al olvido.

74. Es decir, el RGPD establece una ponderación entre esos derechos, pero no excluye que los Estados miembros puedan, en ciertos casos, atribuir un peso mayor o menor a cada uno de los derechos en liza y "salir", en consecuencia, del denominador común constituido por el texto europeo. Si se tiene en cuenta el mecanismo de cooperación entre autoridades que el RGPD prevé y al que se ha hecho referencia, puede pensarse que estas situaciones se producirán solo cuando aquella no fuera posible y, en consecuencia, en supuestos excepcionales. En esas circunstancias cabría entender que las reglas estatales que responden a una ponderación de derechos fundamentales y que no pueden coordinarse con las establecidas en otros Estados miembros, resultarían tan relevantes para ese Estado que se impondrían a sus tribunales en tanto que normas de policía.

75. En el contexto en el que nos situamos, en el que no resulta de aplicación el Reglamento Roma II, no es posible acudir a su artículo 16 para justificar a través de él el recurso a la ley del foro en tanto que "ley de policía" 59 , si bien esta posibilidad cabría de admitirse la solución de lege ferenda antes expuesta. En todo caso, al mismo resultado se puede llegar en el contexto de las normas conflictuales de Derecho autónomo, si se tiene en cuenta que, en los casos excepcionales a los que se está haciendo referencia, el foro estaría proyectando su concepción de sus derechos fundamentales como regla internacionalmente imperativa. Siguiendo esta construcción, incluso de entender que se sigue la regla del Estado para el que se reclama la protección y que, por ejemplo, esta regla condujera a la aplicación de la ley estadounidense, con la consecuente negativa a la retirada de enlaces, el Derecho español podría justificar la exigencia de una retirada global.

76. Si se piensa en las situaciones en las que se puede plantear la situación descrita, una posible lectura de esta excepción consiste en entender que el TJUE está considerando el derecho al olvido no como un derecho autónomo, en el sentido en que se ha venido describiendo hasta ahora, sino como un mecanismo coadyuvante en la defensa de otros derechos fundamentales, como el derecho al honor, por ejemplo. Recuérdese que la finalidad del RGPD es salvaguardar todos los derechos y libertades fundamentales en el contexto del tratamiento de los datos personales ${ }^{60}$.

77. Desde esa perspectiva, el derecho a la protección de datos en ocasiones entra en conflicto con otras libertades, como la libertad de expresión e información, y en otras confluye, en su necesidad de defensa, con la de otros derechos, como el derecho a la intimidad. Esto ocurre, por ejemplo, en un supuesto de difamación en el que los contenidos difamatorios se difunden a través de la web, a partir de la búsqueda del nombre de una persona. La protección de los datos operaría incluso sin la calificación de difamatoria de la información y, en consecuencia, sin necesidad de que ésta cause un daño al individuo. El control sobre los propios datos justifica que un individuo tenga derecho a la supresión de los mismos, simplemente porque no quiere que sean accesibles al público y, en tales casos, el derecho se verá limitado en el sentido establecido en el artículo 17 del RGPD y tendrá el alcance territorial intra-Unión Europea que el TJUE le atribuye. Si no se trata solo de una voluntad de control, sino que está en juego asimismo el derecho a la propia imagen, la cuestión se plantea en otros términos, que exceden del RGPD y que dejan mayor margen de maniobra a los Derechos nacionales, en la medida en que la propia Unión Europea no ha hecho una ponderación de intereses a través de legislación secundaria, similar a la que el RGPD hace cuando se trata del derecho contenido en el artículo 8 de la Carta ${ }^{61}$.

\footnotetext{
${ }^{59}$ Según este "Las disposiciones del presente Reglamento no afectarán a la aplicación de las disposiciones de la ley del foro en aquellas situaciones en que tengan carácter imperativo, cualquiera que sea la ley aplicable a la obligación extracontractual”.

${ }^{60}$ J. Ausloos, The Right..., cit., p. 82.

${ }_{61}$ Desde esta perspectiva podría analizarse, por ejemplo, la sentencia del TJUE de 3 de octubre de 2019 en el asunto C-18/18, Glaswisching-Piesczek, en la que el TJUE acepta la retirada global de enlaces, si bien sujeta su afirmación a no pocas
} 
78. Más difícil resulta el encaje de la segunda de las excepciones: la posibilidad de que en ocasiones la retirada de enlaces se limite al territorio de uno o varios Estados miembros de la Unión Europea. Incluso si se parte de la base de que esto solo resulta planteable en situaciones excepcionales, la postura sostenida por el Abogado General Szpunar en sus conclusiones ${ }^{62}$ se acomoda mejor a la naturaleza y la finalidad del RGPD. Según este, cuyas conclusiones se referían a la Directiva 95/46, dado que esta "tiene por objeto asegurar un alto nivel de protección dentro de la Unión instaura un sistema completo de protección de datos que rebasa las fronteras nacionales" y se enmarca en una lógica de marcado interior que implica un espacio sin fronteras interiores, "una retirada de enlaces a nivel nacional iría en contra de ese objetivo de armonización y efecto útil de las disposiciones de la Directiva 95/46". De ser de aplicación el RGPD, añade, la cuestión ni siquiera llegaría a plantearse, dado que este es directamente aplicable en los Estados miembros y, además, trasciende del planteamiento del mercado interior y, con base en el artículo 16 del TFUE, pretende instaurar un sistema completo de protección de datos personales en la Unión Europea ${ }^{63}$.

79. Las razones por las que el TJUE se separa de esta postura invocando, de nuevo, el artículo 85 del RGPD, no resultan suficientemente explicadas en la sentencia y parece que la retirada solo parcial de enlaces se debería reservar para situaciones que pudieran calificarse de "importancia menor", con todas las dificultades que encierra la precisión de este concepto. La referencia del tribunal al citado artículo 85 hace pensar que, de nuevo, aquí habría que aplicar un criterio conflictual, de manera que si en el Estado miembro en el que se pide la retirada de los enlaces se entiende que basta con hacerlo en él y no en otros Estado, la cuestión no se pueda decidir únicamente en aplicación de la ley del foro, sino teniendo en cuenta la respuesta a la que conducirían las leyes de los demás Estados miembros. No obstante, no parece que sea eso lo que deba inferirse de la sentencia, sino únicamente la exigencia de que la autoridad competente realice una valoración en función de las circunstancias del caso concreto, que le permita evaluar el impacto transfronterizo de la situación y decidir una retirada local de enlaces cuando entiende que el impacto en otros Estados miembros es insignificante.

\section{Conclusiones}

80. El RGPD ha establecido un sistema completo para la protección de los datos personales en el territorio de la Unión Europea que pretende proporcionar soluciones uniformes en todos los Estados miembros, sin perjuicio de las cuestiones que deja a los Derechos nacionales que hacen que esa uniformidad sea solo relativa.

81. Desde la óptica del Derecho internacional privado, el RGPD plantea interrogantes todavía no resueltos tanto en lo que se refiere a la competencia judicial internacional (piénsese, por ejemplo, en la discusión doctrinal acerca de la compatibilidad de los foros establecidos en su artículo 79 con los del Reglamento de Bruselas I bis o las cuestiones que suscita el ejercicio de posibles acciones colectivas), como desde la del Derecho aplicable en las relaciones ad intra, en los supuestos en que el RGPD se re-

cautelas, de manera que se aleja solo de manera muy relativa de lo afirmado en el asunto C-507/17 (sobre esta cuestión, P. DE MIGUEL ASENSIO, "Alcance de los mandamientos judiciales de retirada de contenidos ilícitos frente a redes sociales: la sentencia Glaswisching-Piesczek", en https://pedrodemiguelasensio.blogspot.com/2019/10/alcance-de-los-mandamientos-judiciales. html; A. LóPEZ-TARRUELLA, "El ámbito territorial...", cit., pp. 29-34). La cuestión no se plantea en ese caso en aplicación del RGPD, sino de las normas generales de Derecho civil y en el contexto de la Directiva 2000/31/CE del Parlamento Europeo y del Consejo, de 8 de junio de 2020, relativa a determinados aspectos jurídicos de los servicios de la sociedad de la información, en particular el comercio electrónico en el mercado interior (DOUE L 178, de 17 de julio de 2000) y se refería a la demanda de una política austriaca para que se retirase de Facebook información que le concernía y que parecía vincularla con comportamientos delictivos. Dicha retirada se planteaba como medida cautelar, en tanto que resolvía sobre la acción en cesación con base en el contenido difamatorio de la información.

${ }^{62}$ Conclusiones en el asunto C-507/17, cit.

63 Apartados 76 y 77 de las Conclusiones. 
mite a los Estados miembros. Su todavía reciente adopción, y aún más reciente entrada en vigor, hacen, además, que no dispongamos de criterios jurisprudenciales para dar respuesta a estas cuestiones.

82. Además de lo señalado, la posición adoptada por el TJUE en relación con el ámbito de aplicación del derecho al olvido en el asunto C- 507/17, si bien viene a aclarar algunas preguntas que habían quedado sin respuesta tras la sentencia en el asunto C- 131/12, permite plantear otras nuevas.

83. Desde esa perspectiva, la ponderación que el RGPD hace entre el derecho a la protección de datos y otros derechos- como la libertad de expresión e información- también reconocidos en la Carta de los derechos fundamentales de la Unión Europea, se limita al territorio de los Estados miembros de ésta y no pretende imponerse más allá de sus fronteras.

84. Siendo así, y en relación con el derecho al olvido, el límite territorial a que lo sujeta el TJUE complementa al artículo 3 del RGPD, con la consecuencia de que el RGPD se aplica a las situaciones que este contempla, pero con alcance solo en los Estados miembros de la Unión Europea, lo que deja abierta la cuestión de qué ordenamiento aplicar cuando el interesado pretende una protección que excede las fronteras de aquella.

85. La materia puede analizarse desde una doble perspectiva que se plantea en este trabajo como una contribución al análisis, más que como una respuesta cerrada: la primera conduce a la conclusión de que el RGPD se limita a determinar de manera unilateral su propio ámbito territorial, sin ocuparse de la posible aplicación de otras leyes a las situaciones a las que él mismo no alcanza. La segunda parte del uso del método conflictual y supone considerar que el artículo 3 del RGPD no opera al margen de las normas de conflicto, sino que el texto europeo solo resulta aplicable si lo es en virtud de aquellas y que, únicamente una vez constatado que es así, entraría en juego su artículo 3. Desde esta lectura, se puede hacer cierto paralelismo entre el tratamiento conflictual de las reclamaciones por daños que resultan de la violación de los derechos de propiedad intelectual y las que derivan de la vulneración del derecho al olvido, teniendo en cuenta el alcance territorial de ambos derechos (aunque la del segundo sea una territorialidad que, salvo en supuestos excepcionales, alcanza a toda la Unión Europea). Siendo así, considerar que la norma de conflicto para estos casos es la lex loci damni, entendiendo que el daño se produce en el territorio para el que se reclama la protección resulta una interpretación razonable. 